\title{
Tendências ocupacionais no Exército Brasileiro (1998-2012)
}

Frederico Carlos de Sá Costa*

\section{Resumo}

Ao final do primeiro ano na Academia Militar das Agulhas Negras (AMAN), o cadete escolhe, por ordem de classificação e a partir das vagas oferecidas, em que Arma, Quadro ou Serviço irá permanecer por toda sua carreira. De 1998 a 2012 verificase que as vagas que primeiro são preenchidas são as do Quadro de Material Bélico e do Serviço de Intendência. O presente artigo tenta compreender essa tendência dentro da profissionalização militar a partir da hipótese de que está em sua gênese a transformação da visão que o oficial tem do Exército Brasileiro, de instituição para organização. Sublinhando a análise temos a expectativa de desempenho da função militar no Brasil, a orfandade militar e a profissionalização militar. A proposta teórica utilizada para a compreensão dos dados que indicam a preferência dos cadetes mais antigos pelo Quadro de Material Bélico e pelo Serviço de Intendência será a institucional/ocupacional, segundo a perspectiva de Moskos. A hipótese que orienta este artigo é a de que, no período considerado, os cadetes mais antigos tendem a encarar a carreira no Exército como um emprego como outro qualquer.

Palavras-chave: profissionalização militar, modelo institucional/organizacional, exercício da função militar, orfandade militar.

\footnotetext{
* Universidade Federal Fluminense, Niterói, RJ, Brasil.
} 


\section{Occupational trends in the Brazilian Army (1998-2012)}

\section{Abstract}

At the end of the first year at the Academia Militar das Agulhas Negras (AMAN), the cadet chooses, in order of classification and from the positions offered, at what branch he will remain throughout his career. It was observed that, from 1998 to 2012, the positions that are first filled are those of the Ordnance Corps and the Quartermaster Corps. The present article seeks to understand this tendency within the military professionalization, suggesting that in its genesis lies a change in the officers' understanding of the Brazilian Army, from an institution to an organization. Underlining the analysis there's the expectation of performance of the military function in Brazil, the military orphanhood and military professionalization. The data indicating the preference of the senior cadets for the Ordnance Corps and Quartermaster Corps are analyzed through the theoretical institutional/occupational perspective, as proposed by Moskos. The hypothesis that guides this article is that, during the studied period, the senior cadets tend to consider the career in the Army like any other job.

Keywords: military professionalization, institutional/organizational model, performance of the military function, military orphanage.

\section{Introdução}

o final do primeiro ano na Academia Militar das Agulhas Negras
(AMAN), o cadete escolhe, por ordem de classificação e a partir das
vagas oferecidas, em que Arma, Quadro ou Serviço irá permanecer por toda sua carreira. De 1998 a 2012, verifica-se que as vagas que primeiro são preenchidas são as do Quadro de Material Bélico (MB) e do Serviço de Intendência (INT).

Essa é uma das decisões mais importantes da carreira do militar, tendo em vista que seu perfil profissional, suas perspectivas na carreira, o lugar social ocupado na Força, as cidades ou locais em que irá trabalhar, os possíveis comandos e chefias que exercerá, a satisfação dos desejos ou sonhos que possuía antes do ingresso nas Forças Armadas, e mesmo sua 
inserção na vida civil após terminado o tempo de serviço e já encaminhado para a reserva, tudo isso é determinado pela decisão de ingressar numa Arma, Quadro ou Serviço específico.

Mas falta ainda dizer a coisa mais importante que o dia da escolha de Arma representa: uma opção definitiva, para toda a carreira do militar. Muitos falam desse momento como "um casamento", porque 'é pra vida toda; se escolher mal, não vai dar certo', enquanto para outros ele é 'pior que um casamento', porque 'não pode mudar'. Depois da escolha feita na Academia, não há a menor possibilidade de mudança de Arma: quem ficar insatisfeito com a Arma na qual ingressou, ou continua insatisfeito ou abandona a carreira (Castro, 1990, p. 53).

Bem se percebe a centralidade desse momento na vida do militar do Exército. Embora haja uma concepção transversal do ethos militar conservador, pessimista quanto à índole humana, emocionalmente ligado à corporação e à Pátria, por exemplo -, a escolha da Arma, Quadro ou Serviço agrega outras singularidades ao militar. Os infantes são os "vibradores", os combatentes da Arma "mais militar", os bitolados; os cavalarianos têm o espírito do "rápido e mal feito", aqueles que desenvolvem iniciativa pessoal e flexibilidade; os artilheiros são os militares meticulosos e os mais limpos, técnicos e estudiosos, que não podem provocar um acidente de tiro; os engenheiros são da Arma que "gosta de trabalhar" e que se dá bem com todas as outras Armas, são os mais feios, os atarracados; os intendentes são os que apoiam e suprem, não guerreiam, mas "trabalham com a cabeça", têm maior contato com os civis, são os "gordinhos"; na Arma de Comunicações estão os que atuam junto aos comandantes no combate, são os "sisudos e introspectivos"; finalmente, o Material Bélico agrega os militares que "disputam com a Intendência o título de civis de farda", são os "mecânicos" (Castro, 1990, p. 63-89).

Em linhas gerais, os intendentes são "mestres no suprimento e nas finanças": 
O Serviço de Intendência é a parte da logística voltada para as atividades de suprimento. Ele distribui o material de intendência (uniformes, equipamentos individuais etc.) e os diversos tipos de munição e de gêneros alimentícios. Proporciona também, em operações, outros serviços como lavanderia e banho. Nas organizações militares os intendentes assessoram os comandantes na administração financeira e na contabilidade (Exército Brasileiro, página web).

\section{O Quadro de Material Bélico}

realiza o apoio logístico voltado para a manutenção do material bélico, principalmente, os armamentos, as viaturas e as aeronaves. Inclui-se aí, o suprimento de peças e conjuntos de reparação destinados a esses materiais. Cuida ainda, do suprimento de combustíveis, óleos, graxas e lubrificantes para motores e máquinas (Exército Brasileiro, página web).

Da sumária exposição acima pode-se inferir uma classificação mais geral que distingue o militar combatente do militar não combatente. De um lado, infantes, cavalarianos, artilheiros, engenheiros e, mesmo, a Arma de comunicações; de outro, intendentes e "matbelianos", cuja atividade encontra paralelo nítido com atividades civis. Esperar-se-ia grande intensidade de preferência pelas Armas combatentes, o que, entretanto, não ocorre entre os cadetes mais bem colocados em sua turma de origem. Daí surge a intrigante constatação de que, no período considerado, a preferência dos cadetes se concentra no Material Bélico e na Intendência.

Não há espaço, em um artigo, para discutir todas as dimensões e implicações desse quadro geral de preferências profissionais, entretanto, é possível oferecer uma linha de análise e uma explicação possível a partir do problema apresentado. A vertente analítica aqui utilizada é a da relação instituição/ocupação (Moskos, 1988), tendo como intuito verificar a gênese de uma possível transformação do Exército, de instituição para burocracia ocupacional. Sublinhando a análise, apresentam-se as perspectivas de 
expectativa de desempenho da função ${ }^{1}$ militar (Huntington, 1996), da orfandade militar (Coelho, 2000) e da profissionalização militar (Huntington, 1996; Finer, 2002; Stepan, 1974; Perlmutter, 1977). Função militar como atividade ligada à defesa do Estado, bem como a atuação das Forças Armadas como grupo político de pressão; orfandade compreendida como ausência de interesse político pela agenda militar e ausência de apreço social pelas Forças Armadas; profissionalização militar compreendida como processo para aquisição do conjunto geral de capacidades e habilidades necessárias para a formação e atuação de um oficial. A hipótese que orienta a presente discussão é a de que os oficiais do Exército Brasileiro, ao menos aqueles mais bem colocados em suas turmas de origem, tendem a se orientar profissionalmente na direção de encarar a vida na caserna como um emprego como outro qualquer.

\section{A pesquisa}

Uma observação se faz necessária: muito embora as fontes primárias analisadas neste artigo não sejam sigilosas, são de difícil acesso - muito provavelmente tratadas tão somente como documento de uso institucional, interno. Assim, a discussão aqui estabelecida apresenta-se como um recorte cujo critério foi a possibilidade de obtenção de fonte primária. Apesar da arbitrariedade desse critério (se bem que se saiba que todo recorte é arbitrário), o período analisado (1998-2012) é significativo, pois representa um lapso de 13 anos desde a redemocratização do Brasil, e avança mais 12 anos pelo século XXI. Muitas motivações ideológicas de ingresso na carreira militar já teriam desvanecido (o combate ao comunismo, a guerra insurrecional, o inimigo interno, para citar alguns), e todo um outro perfil de ação militar teria se estabelecido e consolidado (menos voltado para a guerra tradicional ou a guerra insurrecional, e mais voltado para ações

\footnotetext{
"Função: "contribuição de uma instituição social para a manutenção do sistema no seio do qual ela está em interação com outros" (Boudon, 1990, p. 111). Papel: conceito para "definir a identidade social dos indivíduos (...) está ligado aos conceitos de norma e de modelo cultural" (Boudon, 1990, p. 185).
} 
de intervenção internacional, como missões de paz e/ou assistência humanitária). Dessa forma, o recorte proposto apresenta a vantagem de realçar um período de transformação no perfil profissional exigido dos militares e uma mudança nas expectativas de carreira do aspirante à profissão militar.

O quadro 1, a seguir, construído a partir dos dados disponíveis nos anuários estatísticos da AMAN, expõe o quadro geral das preferências dos cadetes no período considerado. ${ }^{2}$

No intervalo de 15 anos acima considerado, o Quadro de Material Bélico preencheu suas vagas em primeiro lugar sete vezes, o Serviço de Intendência, cinco vezes, Comunicações, uma vez e a Arma combatente por excelência, a Infantaria, duas vezes.

Como é de se esperar, a maior quantidade de vagas encontra-se nas Armas combatentes, com predominância da Infantaria. O sistema de escolha oferece aos cadetes com melhor classificação (mais antigos) na turma escolher primeiro a Arma, Quadro ou Serviço de ingresso. Isso nos autoriza a inferir que a maior parte dos cadetes mais bem classificados na turma escolhe o Quadro de Material Bélico ou o Serviço de Intendência, deixando as vagas restantes para os cadetes com classificação inferior.

Além da constatação da preferência por Material Bélico ou Intendência (12 vezes em 15 anos), é possível verificar que em seis ocasiões (1999, 2000, 2005, 2006, 2009 e 2010) Material Bélico e Intendência foram ou primeira ou segunda opção geral, além de nunca terem fechado suas vagas como última preferência geral. Se houve compulsados ${ }^{3}$, estes não foram intendentes ou matbelianos.

\footnotetext{
${ }^{2}$ INT (Intendência); MB (Material Bélico); INF (Infantaria); CAV (Cavalaria); ART (Artilharia); ENG (Engenharia); COM (Comunicações). Os dados de 1999 a 2002 estão no Anuário Estatístico de 2002.

3"Compulsado" é o militar que não conseguiu, por motivos de antiguidade, ingressar na Arma, Quadro ou Serviço de sua preferência, sendo compelido a adotar uma opção subótima.
} 
Quadro 1 - Ordem de fechamento das Armas, Quadros e Serviços por ano e quantidade de vagas

\begin{tabular}{|c|c|c|c|c|c|c|c|}
\hline Ano & $1^{\mathbf{a}}$ & $2^{\underline{a}}$ & $3^{\underline{a}}$ & $4^{\mathrm{a}}$ & $5^{\underline{a}}$ & $6^{-\mathbf{a}}$ & $7 \underline{\mathbf{a}}$ \\
\hline 1998 & $\begin{array}{c}\text { INT } \\
\text { (68 vagas) }\end{array}$ & $\begin{array}{c}\text { ENG } \\
\text { (44 vagas) }\end{array}$ & $\begin{array}{c}\text { CAV } \\
\text { (58 vagas) }\end{array}$ & $\begin{array}{c}\text { ART } \\
\text { (68 vagas) }\end{array}$ & $\begin{array}{c}\text { MB } \\
\text { (34 vagas) }\end{array}$ & $\begin{array}{c}\text { COM } \\
\text { (48 vagas) }\end{array}$ & $\begin{array}{c}\text { INF } \\
\text { (165 vagas) }\end{array}$ \\
\hline 1999 & $\begin{array}{c}\text { INT } \\
\text { (68 vagas) }\end{array}$ & $\begin{array}{c}\text { MB } \\
\text { (34 vagas) }\end{array}$ & $\begin{array}{c}\text { ART } \\
\text { (69 vagas) }\end{array}$ & $\begin{array}{c}\text { INF } \\
\text { (166 vagas) }\end{array}$ & $\begin{array}{c}\text { COM } \\
\text { (49 vagas) }\end{array}$ & $\begin{array}{c}\text { CAV } \\
\text { (59 vagas) }\end{array}$ & $\begin{array}{c}\text { ENG } \\
\text { (44 vagas) }\end{array}$ \\
\hline 2000 & $\begin{array}{c}\text { MB } \\
\text { (32 vagas) }\end{array}$ & $\begin{array}{c}\text { INT } \\
\text { (65 vagas) }\end{array}$ & $\begin{array}{c}\text { COM } \\
\text { (47 vagas) }\end{array}$ & $\begin{array}{c}\text { ENG } \\
\text { (42 vagas) }\end{array}$ & $\begin{array}{c}\text { INF } \\
\text { (158 vagas) }\end{array}$ & $\begin{array}{c}\text { CAV } \\
\text { (56 vagas) }\end{array}$ & $\begin{array}{c}\text { ART } \\
\text { (65 vagas) }\end{array}$ \\
\hline 2001 & $\begin{array}{c}\text { INT } \\
\text { (57 vagas) }\end{array}$ & $\begin{array}{c}\text { COM } \\
\text { (43 vagas) }\end{array}$ & $\begin{array}{c}\text { MB } \\
\text { (39 vagas) }\end{array}$ & $\begin{array}{c}\text { ART } \\
\text { (72 vagas) }\end{array}$ & $\begin{array}{c}\text { INF } \\
\text { (162 vagas) }\end{array}$ & $\begin{array}{c}\text { ENG } \\
\text { (43 vagas) }\end{array}$ & $\begin{array}{c}\text { CAV } \\
\text { (62 vagas) }\end{array}$ \\
\hline 2002 & $\begin{array}{c}\text { MB } \\
\text { (38 vagas) }\end{array}$ & $\begin{array}{c}\text { ART } \\
\text { (70 vagas) }\end{array}$ & $\begin{array}{c}\text { INT } \\
\text { (57 vagas) }\end{array}$ & $\begin{array}{c}\text { COM } \\
\text { (43 vagas) }\end{array}$ & $\begin{array}{c}\text { INF } \\
\text { (161 vagas) }\end{array}$ & $\begin{array}{c}\text { ENG } \\
\text { (43 vagas) }\end{array}$ & $\begin{array}{c}\text { CAV } \\
\text { (62 vagas) }\end{array}$ \\
\hline 2003 & $\begin{array}{c}\text { MB } \\
\text { (28 vagas) }\end{array}$ & $\begin{array}{c}\text { ART } \\
\text { (54 vagas) }\end{array}$ & $\begin{array}{c}\text { INT } \\
\text { (42 vagas) }\end{array}$ & $\begin{array}{c}\text { COM } \\
\text { (32 vagas) }\end{array}$ & $\begin{array}{c}\text { INF } \\
\text { (120 vagas) }\end{array}$ & $\begin{array}{c}\text { ENG } \\
\text { (32 vagas) }\end{array}$ & $\begin{array}{c}\text { CAV } \\
\text { (46 vagas) }\end{array}$ \\
\hline 2004 & $\begin{array}{c}\text { MB } \\
\text { (27 vagas) }\end{array}$ & $\begin{array}{c}\text { ART } \\
\text { (57 vagas) }\end{array}$ & $\begin{array}{c}\text { INT } \\
\text { (46 vagas) }\end{array}$ & $\begin{array}{c}\text { INF } \\
\text { (138 vagas) }\end{array}$ & $\begin{array}{c}\text { COM } \\
\text { (27 vagas) }\end{array}$ & $\begin{array}{c}\text { CAV } \\
\text { (50 vagas) }\end{array}$ & $\begin{array}{c}\text { ENG } \\
\text { (38 vagas) }\end{array}$ \\
\hline 2005 & $\begin{array}{c}\text { MB } \\
\text { (27 vagas) }\end{array}$ & $\begin{array}{c}\text { INT } \\
\text { (47 vagas) }\end{array}$ & $\begin{array}{c}\text { ART } \\
\text { (60 vagas) }\end{array}$ & $\begin{array}{c}\text { CAV } \\
\text { (51 vagas) }\end{array}$ & $\begin{array}{c}\text { COM } \\
\text { (27 vagas) }\end{array}$ & $\begin{array}{c}\text { ENG } \\
\text { (39 vagas) }\end{array}$ & $\begin{array}{c}\text { INF } \\
\text { (141 vagas) }\end{array}$ \\
\hline 2006 & $\begin{array}{c}\text { MB } \\
\text { (35 vagas) }\end{array}$ & $\begin{array}{c}\text { INT } \\
\text { (63 vagas) }\end{array}$ & $\begin{array}{c}\text { COM } \\
\text { (26 vagas) }\end{array}$ & $\begin{array}{c}\text { ART } \\
\text { (62 vagas) }\end{array}$ & $\begin{array}{c}\text { CAV } \\
\text { (63 vagas) }\end{array}$ & $\begin{array}{c}\text { ENG } \\
\text { (50 vagas) }\end{array}$ & $\begin{array}{c}\text { INF } \\
\text { (146 vagas) }\end{array}$ \\
\hline 2007 & $\begin{array}{c}\text { MB } \\
\text { (33 vagas) }\end{array}$ & $\begin{array}{c}\text { COM } \\
\text { (29 vagas) }\end{array}$ & $\begin{array}{c}\text { INT } \\
\text { (58 vagas) }\end{array}$ & $\begin{array}{c}\text { ART } \\
\text { (63 vagas) }\end{array}$ & $\begin{array}{c}\text { INF } \\
\text { (133 vagas) }\end{array}$ & $\begin{array}{c}\text { CAV } \\
\text { (58 vagas) }\end{array}$ & $\begin{array}{c}\text { ENG } \\
\text { (42 vagas) }\end{array}$ \\
\hline 2008 & $\begin{array}{c}\text { COM } \\
\text { (32 vagas) }\end{array}$ & $\begin{array}{c}\text { MB } \\
\text { (32 vagas) }\end{array}$ & $\begin{array}{c}\text { INT } \\
\text { (60 vagas) }\end{array}$ & $\begin{array}{c}\text { ART } \\
\text { (65 vagas) }\end{array}$ & $\begin{array}{c}\text { INF } \\
\text { (156 vagas) }\end{array}$ & $\begin{array}{c}\text { CAV } \\
\text { (64 vagas) }\end{array}$ & $\begin{array}{c}\text { ENG } \\
\text { (51 vagas) }\end{array}$ \\
\hline 2009 & $\begin{array}{c}\text { INT } \\
\text { (48 vagas) }\end{array}$ & $\begin{array}{c}\text { MB } \\
\text { (29 vagas) }\end{array}$ & $\begin{array}{c}\text { INF } \\
\text { (114 vagas) }\end{array}$ & $\begin{array}{c}\text { ART } \\
\text { (55 vagas) }\end{array}$ & $\begin{array}{c}\text { COM } \\
\text { (26 vagas) }\end{array}$ & $\begin{array}{c}\text { ENG } \\
\text { (44 vagas) }\end{array}$ & $\begin{array}{c}\text { CAV } \\
\text { (51 vagas) }\end{array}$ \\
\hline 2010 & $\begin{array}{c}\text { INT } \\
\text { (55 vagas) }\end{array}$ & $\begin{array}{c}\text { MB } \\
\text { (34 vagas) }\end{array}$ & $\begin{array}{c}\text { INF } \\
\text { (135 vagas) }\end{array}$ & $\begin{array}{c}\text { COM } \\
\text { (30 vagas) }\end{array}$ & $\begin{array}{c}\text { ENG } \\
\text { (47 vagas) }\end{array}$ & $\begin{array}{c}\text { ART } \\
\text { (63 vagas) }\end{array}$ & $\begin{array}{c}\text { CAV } \\
\text { (59 vagas) }\end{array}$ \\
\hline 2011 & $\begin{array}{c}\text { INF } \\
\text { (131 vagas) }\end{array}$ & $\begin{array}{c}\text { INT } \\
\text { (61 vagas) }\end{array}$ & $\begin{array}{c}\text { COM } \\
\text { (35 vagas) }\end{array}$ & $\begin{array}{c}\text { MB } \\
\text { (35 vagas) }\end{array}$ & $\begin{array}{c}\text { ENG } \\
\text { (48 vagas) }\end{array}$ & $\begin{array}{c}\text { CAV } \\
\text { (61 vagas) }\end{array}$ & $\begin{array}{c}\text { ART } \\
\text { (65 vagas) }\end{array}$ \\
\hline 2012 & $\begin{array}{c}\text { INF } \\
\text { (120 vagas) }\end{array}$ & $\begin{array}{c}\text { CAV } \\
\text { (60 vagas) }\end{array}$ & $\begin{array}{c}\text { ART } \\
\text { (60 vagas) }\end{array}$ & $\begin{array}{c}\text { INT } \\
\text { (55 vagas) }\end{array}$ & $\begin{array}{c}\text { COM } \\
\text { (32 vagas) }\end{array}$ & $\begin{array}{c}\text { MB } \\
\text { (32 vagas) }\end{array}$ & $\begin{array}{c}\text { ENG } \\
\text { (55 vagas) }\end{array}$ \\
\hline
\end{tabular}

Fonte: Elaborado pelo autor, a partir de informações dos Anuários Estatísticos do Ministério da Defesa, 2002 a 2012.

O perfil profissiográfico do egresso da AMAN não oferece muitos elementos para a compreensão da escolha privilegiada pelo Material Bélico e pela Intendência. As informações sobre as finalidades do curso da Academia, as competências e os eixos profissionais são muito parecidos entre si. As mudanças, quando há, restringem-se a especificar comandos 
(infantes comandam frações de infantaria, intendentes de intendência, e matbelianos de material bélico) ou atividades próprias de cada área de atuação. Em termos de origem socioeconômica, os dados disponíveis demonstram o perfil de classe média dos cadetes (dados disponíveis a partir de 2003), cuja renda familiar declarada concentra-se na faixa de 6 a 10 salários mínimos. ${ }^{4}$ Os dados acima não permitem que se esclareça a problemática da escolha privilegiada pelo Quadro de Material Bélico e o Serviço de Intendência: a ordem de fechamento das vagas não tem relação necessária e suficiente com a quantidade de vagas oferecidas; o perfil profissiográfico é por demais genérico para que dele se possam extrair conclusões que indiquem a maior ou menor propensão do cadete para uma área específica da atividade militar, tendo em vista que o perfil geral da atividade profissional é muito similar; o padrão geral de origem socioeconômica dos cadetes (a classe média) é consistente com dados coletados desde a década de 40 do século XX (Stepan, 1974).

Assim, os dados, por si sós, são um ponto de partida. O esforço compreensivo prossegue, dessa forma, esclarecendo o que significa "expectativa de desempenho da função militar", orfandade e profissionalização para, em seguida, discutir como se podem interpretar os dados a partir da perspectiva organizacional/ocupacional.

Em seus termos mais amplos, a função militar concentra-se na defesa do Estado contra o inimigo, aquele que ameaça a ordem sociopolítica vigente, quer se trate de inimigo externo ou interno. Num sentido mais estrito, ela pode ser compreendida como uma parte da política de segurança nacional, ou seja, a política de segurança militar, que pretende prover o Estado dos meios militares necessários à sua preservação e perpetuação no tempo. Isso se dá num sentido quantitativo (efetivos, recrutamento, estado de prontidão militar) e qualitativo (organização, programas de ação, planejamento com aliados) (Huntington, 1996). No sentido do aperfeiçoamento da política de segurança militar, leva-se em conta a especialização do oficial (como se dá a especialização na administração da violência em termos

${ }^{4}$ Maiores detalhes em Oliveira (2015). 
de organização, planejamento e capacidade de direção em combate), a responsabilidade do oficialato em termos sociais e políticos (a defesa do Estado sem comprometimento da ordem social e política) e o espírito corporativo dos militares ou sua capacidade de se reconhecerem como elementos de uma instituição específica (Huntington, 1996).

Por outro lado, a função militar se exerce muito nitidamente no sentido da composição das Forças Armadas como um grupo de pressão política, uma instituição que pressiona e busca o poder político para o diálogo e a consecução dos recursos de diversas naturezas necessários para a obtenção da segurança militar nacional (Janowitz, 1964). Ainda nesse sentido político, a função militar compreende a presença do profissional das armas como o elemento de ajuste dos instrumentos de violência necessários à consecução dos objetivos nacionais nas relações internacionais, sempre segundo uma dada doutrina profissional que é devedora do ambiente social nacional (Janowitz, 1964).

A partir do exposto, compreende-se função militar ${ }^{5}$, para os efeitos deste artigo, como uma atividade profissional de duplo gume: o planejamento e a operação de atividades militares stricto sensu que objetivem a consecução da sensação de segurança em um dado Estado; e o exercício de pressão política em prol da satisfação das necessidades e da agenda militar nos planos interno e externo (preferencialmente, em concordância com os objetivos políticos).

Em parágrafos anteriores, foi apresentado um entendimento sumário de profissionalização militar: a aquisição do conjunto geral de capacidades e habilidades necessárias para a formação e atuação de um oficial, quer seja no sentido instrumental, de defesa territorial do Estado, quer seja no sentido político. Algum aprofundamento nesse entendimento, no entanto, se faz necessário.

Dois conjuntos complementares de características podem ser apresentados para caracterizar uma profissão conforme Huntington (1996):

${ }^{5}$ Deve-se entender "função militar" como um tipo ideal, um conceito mediado pelas condições intrínsecas a cada Estado. 
a) especialização; b) responsabilidade; e c) espírito de corpo. Em Perlmutter (1977): a) padrões universais para julgar casos específicos; b) especialização profissional; c) asserção de autoridade (o cliente confia no profissional); d) relação impessoal com o cliente; e) julgamento de performance segundo princípios estabelecidos; e f) proteção do cliente como um fim em si mesmo.

Compreendendo as características acima em termos da profissionalização militar, deve-se levar em conta: especialização na administração da violência; responsabilidade, fidelidade e impessoalidade no trato com um cliente muito singular, o Estado e sua população, que devem ser ciosamente protegidos; reconhecimento mútuo e solidário entre militares, todos como parte de uma instituição com valores próprios; um regulamento capaz de oferecer critérios para nivelar opiniões, julgar performance e resolver conflitos; crença do Estado e da população na capacidade do militar em cumprir sua função.

Não se deve considerar que profissionalização militar é um conjunto de atividades homogêneo com um objetivo único, pelo contrário. Apesar de a obra de Huntington ter se tornado uma espécie de "literatura oficial" quando se trata da relação civil-militar, alguns pontos requerem crítica. Segundo o autor de $O$ soldado e o Estado, "política de segurança militar é o programa de atividades destinado a minimizar ou neutralizar esforços tendentes a enfraquecer um país através de forças armadas que operam de fora de suas fronteiras institucionais e territoriais" (Huntington, 1996, p. 19). O responsável pela execução dessa política é o profissional militar, o especialista na administração da violência, aquele que tem por meta o "combate armado bem-sucedido", reconhece sua profissão como "técnica e limitada" (Huntington, 1996, p. 29, 88) e vê a política situada além da área de abrangência de sua profissão. O profissional militar é "politicamente neutro" (Huntington, 1996). A relação pensada por Huntington indica que, quanto mais a liderança política reconhece a autonomia militar no domínio da especialização na administração da violência, mais o militar reconhece a esfera política como responsável pelas decisões relativas à segurança estatal. Nessas condições, prevalece o que o autor chama de controle civil objetivo. 
Percebe-se que, em Huntington, a profissionalização tem um sentido claro: a administração da violência para que se minimizem ou neutralizem os esforços tendentes a enfraquecer um país através de forças armadas que operam de fora de suas fronteiras institucionais e territoriais. Assim profissionalizado, o militar não interferiria na política.

A crítica ao posicionamento de Huntington surge rapidamente. Para Samuel Finer (2002), a profissionalização militar não tem um sentido único, direcionado para ameaças externas. E mais: para Finer, a profissionalização pode, ao invés de afastar, precipitar o militar para a política, dependendo de como um dado país se encontra em termos de cultura política:

(...) em países de cultura política madura, os militares influenciam a política através dos canais institucionais legalmente estabelecidos, leais ao regime civil. Em situações de cultura política desenvolvida, o nível de intervenção oscila da influência à chantagem, sendo possível que se verifique algum tipo de intimidação ou ameaça de violência contra as autoridades civis. Nos países de cultura política baixa, a intervenção oscila da chantagem à imposição da substituição das autoridades políticas civis estabelecidas, configurando-se um regime civil/militar. Nos países de cultura política mínima, a influência militar constrange o ambiente político a ponto de depor governantes e impor a violência como método sistemático de resolução de conflitos (Costa, 2015, p. 117).

Em outras palavras, cultura política é o grau de consenso em relação ao domínio vigente. Quanto mais alto, mais as Forças Armadas se profissionalizam em termos de ameaças externas e são obedientes ao Estado. Quanto mais baixo, mais as Forças Armadas profissionalizam-se em termos da defesa (ou subversão) do regime, de si mesmas ou de alguma noção autogestada de bem-comum. Um militar profissional pode, então, especializar-se em intervenção política, ao contrário do que pensava Huntington.

Perlmutter (1977) afirma que o profissional militar é um profissional corporativo. Assim, a profissionalização se dá no ambiente político em que o corporativismo militar opera. Onde prevalecem as características do Estado Moderno racional-legal, o militar tende à profissionalização de perfil 
huntingtoniano. Entretanto, se o ambiente político for de perfil pretoriano (grande politização da sociedade civil em face de instituições políticas fracas), a profissionalização se dá na direção da intervenção na política. Nos ambientes revolucionários, a profissionalização opera no sentido de fazer do militar um agente fiel a uma causa ou a um líder que encarna valores que devem ser obedecidos em si mesmos:

O soldado pretoriano apresenta seu tipo ideal na América Latina e mostra, em uma sociedade altamente politizada, mas com poucos canais institucionais ou sociais para canalização e processamento das demandas políticas, como um militar profissional pode usar a profissão como uma plataforma para ação política, principalmente quando o regime vigente ameaça a integridade da corporação militar. O soldado revolucionário, se bem que profissional, coloca o corporativismo em segundo plano, por estar sujeito a um ambiente político cuja influência é impossível de resistir. A força da causa revolucionária, ou o carisma do líder subjugam o corporativismo militar e constituem o locus da lealdade (Costa, 2015, p. 118).

Nesse ponto, é possível apontar uma aproximação com sociedades como a brasileira, de perfil pretoriano. Nessas sociedades, todos os grupos tentam cooptar os militares a fim de aumentar seu próprio poder político (Stepan, 1974, p. 62), incrementando o que este autor denomina como "nova profissionalização" (ver Quadro 2).

Portanto, não se pode considerar a profissionalização militar como uma atividade sem transigências com o contexto do Estado em questão. Profissionalizar pode significar afastar o militar da política, mas também pode significar o contrário.

Edmundo Campos Coelho (2000, p. 19) afirma que "não é de hoje que os militares brasileiros queixam-se de uma desagradável e dupla orfandade". Em primeiro lugar, uma orfandade funcional, a crença de que sociedade e políticos os consideram desnecessários, principalmente num momento em que não há nenhuma perspectiva de conflito regional e nem a mais remota possibilidade de fazer frente às potências nucleares. Em segundo lugar, uma orfandade institucional, a convicção de que não 
há interesse político pela agenda militar de segurança nacional (Coelho, 2000). A dupla orfandade seria uma das origens da tendência militar, no Brasil, de assumir posição protagonista e/ou autônoma.

Quadro 2

\begin{tabular}{|l|l|l|}
\hline Função dos militares & \multicolumn{1}{|c|}{$\begin{array}{c}\text { Antigo profissionalismo } \\
\text { Segurança externa }\end{array}$} & \multicolumn{1}{|c|}{$\begin{array}{c}\text { Novo profissionalismo } \\
\text { Segurança interna }\end{array}$} \\
\hline $\begin{array}{l}\text { Atitudes civis em } \\
\text { relação ao governo }\end{array}$ & $\begin{array}{l}\text { Civis aceitam a legitimidade } \\
\text { do governo }\end{array}$ & $\begin{array}{l}\text { Parcelas da sociedade } \\
\text { desafiam a legitimidade do } \\
\text { governo }\end{array}$ \\
\hline $\begin{array}{l}\text { Habilidades militares } \\
\text { que são requeridas }\end{array}$ & $\begin{array}{l}\text { Habilidades altamente } \\
\text { especializadas e } \\
\text { incompatíveis com } \\
\text { habilidades políticas }\end{array}$ & $\begin{array}{l}\text { Habilidades militares } \\
\text { e políticas altamente } \\
\text { entrelaçadas }\end{array}$ \\
\hline $\begin{array}{l}\text { Abrangência da ação } \\
\text { militar }\end{array}$ & Restrita & Sem restrições \\
\hline $\begin{array}{l}\text { Impacto da } \\
\text { socialização } \\
\text { profissional }\end{array}$ & $\begin{array}{l}\text { Proporciona neutralidade } \\
\text { política }\end{array}$ & Militares politizados \\
\hline $\begin{array}{l}\text { Impacto nas relações } \\
\text { entre civis e militares }\end{array}$ & $\begin{array}{l}\text { Contribui para controle } \\
\text { militar e político apolítico }\end{array}$ & $\begin{array}{l}\text { Contribui para controle } \\
\text { político militar e para a } \\
\text { expansão do papel militar }\end{array}$ \\
\hline
\end{tabular}

Fonte: Stepan (1973, p. 52, apud McCann Jr., 1979, p. 506).

Ao longo de seu Em busca da identidade, Coelho (2000) constrói a narrativa da relação civil-militar no Brasil a partir do posicionamento do General Góes Monteiro, nas décadas de 30 e 40 do século XX, quem afirmava serem as Forças Armadas as responsáveis pela organização nacional, visto que são as únicas instituições nacionais e permanentes capazes de vencer o "bizantino e inviolável espírito do liberalismo". Dessa posição privilegiada, surgiam Exército e Marinha como órgãos políticos responsáveis pela organização "das demais forças da nacionalidade" (Gen. Góes Monteiro apud Coelho, 2000, p. 115). Nesse momento, são lançadas as bases da Doutrina de Segurança Nacional, que confere lugar e função às Forças Armadas no Brasil, se bem que, afirme-se, fortemente voltadas para o 
controle e manutenção da ordem social. A sucessão de golpes, tentativas de golpes, manifestos e os desgastes impostos às Forças Armadas pelo regime de 1964 construíram outra narrativa, a narrativa da orfandade.

A partir da experiência dos Estados Unidos, Charles Moskos propõe que as Forças Armadas norte-americanas estão em transição, de um modelo organizacional de perfil institucional para outro modelo, de perfil ocupacional. O núcleo do raciocínio está em identificar um continuum entre uma organização nitidamente divergente da sociedade dos civis e uma outra organização, nitidamente convergente com a sociedade dos civis (Moskos, 1988). Tendo em vista que os extremos desse continuum são tipos ideais, o perfil das Forças Armadas de um dado país deve ser procurado em algum ponto entre a máxima institucionalização e a máxima organização/ ocupação, de acordo com o maior ou o menor peso conferido a cada uma das variáveis escolhidas para a aferição da taxonomia proposta. O quadro 3, a seguir, sumariza o debate.

Forças Armadas fortemente convergentes com o perfil "instituição" entendem-se como algo separado e diferente da sociedade em geral, movidas pelo senso de dever ou honra. A partir das variáveis trabalhadas por Moskos, e assumindo a posição mais próxima possível do perfil "instituição", vemos, assim, Forças Armadas legitimadas por valores normativos, verticalizadas, oferecendo a seus recrutas o apelo de um modo de vida específico. Em termos legais, a justiça militar ocupa papel importante, sendo uma das marcas principais da separação militares/civis. As mulheres e esposas ocupam espaço limitado nesse perfil (emprego limitado ou restrita ao papel familiar, respectivamente), residindo, com seus maridos, nas adjacências da organização militar. Não sendo orientadas segundo o mercado, percebe-se que a remuneração ou compensação é pecuniária, mas não só. Os militares da reserva gozam de prerrogativas especiais e distintas dos aposentados da sociedade dos civis (Moskos, 1988).

No outro lado do espectro, no lado organizacional, percebe-se que a orientação segue os preceitos do mercado e que o interesse individual rege a conduta dos indivíduos, havendo pouco espaço para o sentido holístico 
do dever ou da honra. A disposição dos membros da organização tende a ser horizontal e a remuneração predominante é o dinheiro. Em termos legais, vale a jurisprudência e os códigos civis. As mulheres encontram mais espaço profissional e, quando esposas de militares, afastam-se dos papéis designados pela "família militar". Os locais de moradia e de trabalho não são adjacentes e os aposentados seguem o regime salarial geral (Moskos, 1988).

\section{Quadro 3}

\begin{tabular}{|c|c|c|}
\hline Variável & Institucional & Ocupacional \\
\hline $\begin{array}{l}\text { Legitimidade } \\
\text { Estima social }\end{array}$ & $\begin{array}{l}\text { Valores normativos } \\
\text { Estima baseada nas noções } \\
\text { do serviço }\end{array}$ & $\begin{array}{l}\text { Economia de mercado } \\
\text { Prestígio baseado no nível de } \\
\text { remuneração }\end{array}$ \\
\hline $\begin{array}{l}\text { Comprometimento } \\
\text { com a função }\end{array}$ & $\begin{array}{l}\text { Difuso; generalista } \\
\text { Verticalizado na instituição }\end{array}$ & $\begin{array}{l}\text { Especialista } \\
\text { Horizontal em relação às } \\
\text { ocupações não militares }\end{array}$ \\
\hline $\begin{array}{l}\text { Apelo quanto ao } \\
\text { recrutamento }\end{array}$ & $\begin{array}{l}\text { Estilo de vida; qualidades no } \\
\text { caráter }\end{array}$ & $\begin{array}{l}\text { Treinamento técnico; } \\
\text { remuneração alta }\end{array}$ \\
\hline $\begin{array}{l}\text { Avaliação de } \\
\text { performance }\end{array}$ & Holística e qualitativa & Segmentada e quantitativa \\
\hline Base de compensação & Senioridade & Nível de habilidade \\
\hline $\begin{array}{l}\text { Forma de } \\
\text { compensação }\end{array}$ & $\begin{array}{l}\text { Grande parcela em forma } \\
\text { não monetária }\end{array}$ & Salário e/ou bônus \\
\hline Sistema legal & Justiça militar & Jurisprudência civil \\
\hline Papel da mulher & Carreira restrita & Carreira aberta \\
\hline Papel do cônjuge & $\begin{array}{l}\text { Parte integral da } \\
\text { comunidade militar }\end{array}$ & $\begin{array}{l}\text { Retirado da comunidade } \\
\text { militar }\end{array}$ \\
\hline Local de residência & $\begin{array}{l}\text { Adjacências da unidade } \\
\text { militar }\end{array}$ & $\begin{array}{l}\text { Habitação separada do local } \\
\text { de trabalho }\end{array}$ \\
\hline $\begin{array}{l}\text { Status na } \\
\text { aposentadoria ou pós- } \\
\text { serviço }\end{array}$ & $\begin{array}{l}\text { Benefícios e vantagens para } \\
\text { os veteranos }\end{array}$ & $\begin{array}{l}\text { Similar àqueles em serviço } \\
\text { ativo }\end{array}$ \\
\hline
\end{tabular}

Fonte: Moskos (1988, p. 16, tradução livre).

Em se tratando de uma migração dos militares para o perfil organizacional, observar-se-ia, sempre segundo Moskos, um movimento no sentido de se 
diluírem as diferenças entre empreendimentos civis e militares, uma ênfase na remuneração em dinheiro (ao invés de prestígio, honra ou outros fatores distintivos de status), e na criação de um vínculo claro entre remuneração ou compensação por serviço baseada na comparação entre indivíduos em termos de diferenciação de expertise ou maior ou menor capacidade em exercer funções específicas.

Algumas possibilidades podem ser vislumbradas no quadro 4, a seguir.

\begin{tabular}{|c|c|c|c|}
\hline \multicolumn{4}{|c|}{ Quadro 4} \\
\hline & & \multicolumn{2}{|c|}{$\begin{array}{c}\text { Integração externa } \\
\text { Conexões sociais e normativas entre Forças } \\
\text { Armadas e sociedade }\end{array}$} \\
\hline \multirow{3}{*}{$\begin{array}{l}\text { Integração interna } \\
\text { Conexôes sociais e } \\
\text { normativas dentro } \\
\text { das Forças Armadas }\end{array}$} & & Baixo & Alto \\
\hline & Baixo & $\begin{array}{l}\text { Forças Armadas atuais? } \\
\text { (1) }\end{array}$ & $\begin{array}{l}\text { A imagem convergente } \\
\text { do militar ineficaz e } \\
\text { "civilianizado" } \\
\text { (2) }\end{array}$ \\
\hline & Alto & $\begin{array}{l}\text { A imagem divergente do } \\
\text { militar isolado e coeso } \\
\text { (3) }\end{array}$ & $\begin{array}{l}\text { As Forças Armadas do } \\
\text { futuro? } \\
\text { (4) }\end{array}$ \\
\hline \multicolumn{4}{|c|}{$\begin{array}{l}\text { Conexões conceituais com o modelo Institucional/Organizacional } \\
\text { 1. Modelo ocupacional emergente } \\
\text { 2. Modelo pseudo-ocupacional } \\
\text { 3. Modelo pseudo-institucional } \\
\text { 4. Modelo institucional }\end{array}$} \\
\hline
\end{tabular}

Fonte: Cotton (1988, p. 49, tradução livre).

Cotton (1988) aponta como indicadores de baixa integração entre Forças Armadas e sociedade: antipatia da classe média em relação ao serviço militar; base restrita de recrutamento; baixo percentual de participação; alienação das tropas mais jovens (ou dos conscritos); e baixa integração entre o serviço militar e o sistema educacional civil. Como indicadores de baixa coesão interna, teríamos: conflitos internos de atitude; ambiguidade em relação ao status do guerreiro; tensão entre os setores de suporte e os setores operacionais; estranhamento ou alienação dos oficiais mais antigos 
em relação à política; diferenças de pagamento em termos de ocupação; problemas pessoais nas organizações militares; e o carreirismo.

As conexões dentro das Forças Armadas e aquelas entre as Forças Armadas e a sociedade são comparadas e cruzadas. Desse modo, podemos observar se e quando os militares se aproximam do modelo ocupacional. Se há baixa integração militar com baixa ligação entre militares e sociedade, observa-se algo próximo dos militares atuais, com um modelo ocupacional emergente. Se há forte integração militar com fortes conexões com a sociedade, observa-se o representante do modelo institucional.

\section{Conclusão}

A partir do exposto, é possível esboçar um quadro geral compreensivo para os dados apresentados a partir dos anuários estatísticos da AMAN.

Há pouca visibilidade no Brasil quanto à efetiva função militar e às expectativas relativas a seu desempenho. A definição aqui apresentada de função militar foi a de atividade profissional de duplo gume, que abarca práticas militares e exercício de pressão política a favor da agenda militar de segurança. Em se tratando das práticas militares ligadas à segurança nacional, há pouca ou nenhuma hipótese crível de emprego militar em conflito externo, por um lado, e, por outro, as hipóteses de emprego interno estão cobertas por espessa nuvem de incerteza. Em se tratando da atuação do Exército Brasileiro como grupo de pressão política em prol da agenda militar de segurança, apresenta-se a dúvida das elites políticas e da sociedade em relação ao que seja exatamente uma "agenda militar de segurança", externa ou interna.

A profissionalização militar é transitiva com as características do Estado em questão e da sociedade. No Brasil, é preciso que se pense a profissionalização militar transigindo com o pretorianismo. Em outras palavras, a politização de todos os setores da sociedade brasileira não encontra eco nem respaldo nas instituições políticas, conduzindo a duas vias: a cooptação militar e a ocupação dos espaços políticos pela Força 
(já que o consenso quanto ao domínio vigente é frágil). Dessa forma, profissionalizar o militar, no Brasil de Getúlio Vargas até o fim da ditadura, compreende especializá-lo na intervenção política e, por consequência, aproximá-lo canhestramente da sociedade.

A perspectiva militar de espelho organizacional face à dissolução liberal é persistente. A história de intervenções e golpes no Brasil segue essa perspectiva, embora cobrando seu preço à instituição militar. A sensação de orfandade, funcional ou institucional, coloca ao militar a questão de como se posicionar em termos de papel e função social. Uma das saídas possíveis para a resolução da orfandade é a busca por um posicionamento profissional próximo das atividades civis, em que há respaldo social claro.

Quando se completa o número de vagas da Intendência e do Material Bélico antes das vagas oferecidas pelas armas combatentes, oferece-se a clara perspectiva de que os quadros combatentes são menos cobiçados: a) as expectativas de desempenho da função militar se diluíram num ambiente contemporâneo marcado pela aridez ideológica do mercado; b) a profissionalização militar vai se afastando do pretorianismo intervencionista, rumo a uma ênfase maior na compatibilidade com as profissões civis ou políticas (o que não elimina o intervencionismo, mas muda suas características, de chantagem ou derrubada de regime para influência difusa e hegemônica); c) a problemática da orfandade militar pode estar encontrando sua resolução na maior proximidade com as atividades civis ou mesmo com os contextos contemporâneos mais prováveis para emprego militar, como as atividades ligadas à pacificação, que envolvem o componente de força, bem como o componente de (re)organização social e econômica (segurança com desenvolvimento). Os intendentes e matbelianos inserem-se, assim, num quadro mais amplo de exercício profissional.

A perspectiva ocupacional, que mostra a tendência de se encarar a atividade militar como uma profissão qualquer, indica a crescente aproximação das atividades militares daquelas civis, com a consequência de se medir resultados, papel e função social, bem como remuneração e status jurídico, a partir das perspectivas de mercado. Essa perspectiva se 
apresenta como nova variável a se acrescentar ao debate relativo ao Brasil. Levando em conta as hipóteses levantadas no parágrafo anterior, também se deve levar em conta, para a melhor compreensão dos dados oferecidos pelos Anuários Estatísticos da AMAN, a possibilidade de complexificar o caso brasileiro, colocando-o num ponto entre os modelos pseudo-ocupacional e pseudo-institucional, uma gênese de transformação de instituição para organização (os militares, assim, compartilhariam simultaneamente do ônus e do bônus, tanto do extremo institucional quanto do extremo ocupacional). Em outras palavras, o militar ainda é considerado eficaz para as demandas da sociedade brasileira, mas já demonstra um grande percentual de oficiais "civilianizados", embora ainda se mantenha um grau elevado de coesão interna e alguma percepção de distinção em relação aos civis. O militar cuja profissionalização não é a "antiga" (segurança externa, aceitação da legitimidade do governo, especialização incompatível com a política, neutro e sujeito ao controle civil), nem a "nova"/pretoriana (segurança interna, questionadora da legitimidade do governo, especialização potencialmente compatível com a política e não necessariamente sujeito ao controle civil), é um militar, enfim, que gradualmente se move na direção ocupacional.

Assumindo uma projeção de 30 anos de carreira, a partir de 2028 o Exército brasileiro terá uma elite dirigente composta por generais que não necessariamente assumiram sua arma de origem como prioridade profissional (o Alto Comando do Exército é composto por oficiais oriundos das armas combatentes), por não terem sido os cadetes mais antigos no momento da escolha. É sabido que a profissionalização é um processo contínuo, e que os cursos e atividades exercidas ao longo da carreira atuam fortemente no aprimoramento do oficial, entretanto, o que se enfatiza no presente artigo é que o momento mais decisivo da vida do militar, a escolha da Arma, Quadro ou Serviço, é marcado por uma perspectiva muito distinta: a de que a profissão militar é uma profissão como outras, mesmo e apesar de todas as mitologias que envolvem o mundo da caserna. Em países como os Estados Unidos, isso não chega a ser uma novidade, sendo já discutido na academia desde o trabalho de Janowitz (1964). Contudo, no Brasil, 
essa constatação é de grande importância, ainda mais quando se leva em conta as peculiaridades do Exército como grupo de pressão política (afirmar de antemão que uma elite dirigente, composta por oficiais de perfil organizacional/ocupacional, exerceria pressão política com métodos ou objetivos diferentes daqueles conhecidos até hoje seria mera especulação; coerente, entretanto, ainda especulação).

A compreensão dos dados e da dinâmica acima, a partir da perspectiva ocupacional, conduz à conclusão de que um quarto dos cadetes (um número enorme), o quarto mais bem colocado, mais antigo em suas turmas de origem, tende a encarar a profissão militar como mais uma profissão, como um emprego como outro qualquer.

Frederico Carlos de Sá Costa é Doutor em Ciência Política e professor de Teoria Política e Estudos da Defesa no INEST/UFF.

Đf farlos@id.uff.br 


\section{Referências}

1. BOUDON, Raymond. Dicionário de sociologia. Lisboa: Codex, 1990.

2. CASTRO, Celso. O espírito militar. Um estudo de antropologia social na Academia Militar das Agulhas Negras. Rio de Janeiro: Jorge Zahar, 1990.

3. COELHO, Edmundo C. Em busca de identidade: o exército e a política na sociedade brasileira. Rio de Janeiro: Record, 2000.

4. COSTA, Frederico C. de S.. Estudos estratégicos, controle civil e identificação do inimigo. Revista da Escola Superior de Guerra, v. 30, n. 61, p. 112-146, 2015.

5. COTTON, Charles A. The institutional organization model and the military. In: MOSKOS, Charles C.; WOOD, Frank R. The military, more than just a job? Washington: Pergamon-Brassey's, 1988.

6. EXÉRCITO BRASILEIRO. Armas, quadros e serviços [página web oficial]. Ministério da Defesa, s/a. Disponível em: http://www.eb.mil.br/armas-quadrose-servicos/-/asset_publisher/W4kQIILo3SEa/content/servico-de-intendencia?inher itRedirect $=$ false.

7. FINER, Samuel. The man on horseback. Nova Brunswick: Transaction Publishers, 2002.

8. HUNTINGTON, Samuel P. O soldado e o Estado. Teoria e política das relações entre civis e militares. Rio de Janeiro: Biblioteca do Exército, 1996.

9. JANOWITZ, Morris. The professional soldier. A social and political portrait. Londres: The Free Press of Glencoe, 1964.

10. MCCANN JR., Frank D. Origins of the "new professionalism" of the Brazilian Army. Journal of Interamerican Studies and World Affairs, Miami, Center for Latin American Studies at the University of Miami, v. 21, n. 4, p. 505-522, 1979.

11. MOSKOS, Charles C. Institutional and occupational trends in Armed Forces. In: MOSKOS, Charles C.; WOOD, Frank R. The Military, more than just a job? Washington: Pergamon-Brassey's, 1988. p. 15-26.

12. OLIVEIRA, Ana A. P. Profissionalização e educação militar: um estudo a partir da Academia Militar das Agulhas Negras (AMAN). 2015. Dissertação (Mestrado em Estudos Estratégicos) - Instituto de Estudos Estratégicos, Universidade Federal Fluminense, Niterói, 2015.

13. PERLMUTTER, Amos. The military and politics in modern times. New Haven: Yale University Press, 1977.

14. STEPAN, Alfred. The military in politics: changing patterns in Brazil. Nova Jersey: Princeton University Press, 1974. 


\section{Fontes primárias}

1. MINISTÉRIO DA DEFESA - Exército Brasileiro - Academia Militar das Agulhas Negras. Anuário estatístico. Brasília: Ministério da Defesa, 2002.

2. MINISTÉRIO DA DEFESA- Exército Brasileiro - Academia Militar das Agulhas Negras. Anuário estatístico. Brasília: Ministério da Defesa, 2003.

3. MINISTÉRIO DA DEFESA- Exército Brasileiro - Academia Militar das Agulhas Negras. Anuário estatístico. Brasília: Ministério da Defesa, 2004.

4. MINISTÉRIO DA DEFESA- Exército Brasileiro - Academia Militar das Agulhas Negras. Anuário estatístico. Brasília: Ministério da Defesa, 2005.

5. MINISTÉRIO DA DEFESA- Exército Brasileiro - Academia Militar das Agulhas Negras. Anuário estatístico. Brasília: Ministério da Defesa, 2006.

6. MINISTÉRIO DA DEFESA- Exército Brasileiro - Academia Militar das Agulhas Negras. Anuário estatístico. Brasília: Ministério da Defesa, 2007.

7. MINISTÉRIO DA DEFESA- Exército Brasileiro - Academia Militar das Agulhas Negras. Anuário estatístico. Brasília: Ministério da Defesa, 2008.

8. MINISTÉRIO DA DEFESA- Exército Brasileiro - Academia Militar das Agulhas Negras. Anuário estatístico. Brasília: Ministério da Defesa, 2009.

9. MINISTÉRIO DA DEFESA- Exército Brasileiro - Academia Militar das Agulhas Negras. Anuário estatístico. Brasília: Ministério da Defesa, 2010.

10. MINISTÉRIO DA DEFESA- Exército Brasileiro - Academia Militar das Agulhas Negras. Anuário estatístico. Brasília: Ministério da Defesa, 2011.

11. MINISTÉRIO DA DEFESA- Exército Brasileiro - Academia Militar das Agulhas Negras. Anuário estatístico. Brasília: Ministério da Defesa, 2012. 